Article

\title{
New Dispatching Paradigm in Power Systems Including EV Charging Stations and Dispersed Generation: A Real Test Case
}

\author{
Fabio Cazzato ${ }^{1}$, Marco Di Clerico ${ }^{1}$, Maria Carmen Falvo ${ }^{2, *} \mathbb{D}$, Simone Ferrero ${ }^{1}$ and \\ Marco Vivian ${ }^{2}$ \\ 1 E-Distribuzione, Enel Group, 00198 Rome, Italy; fabio.cazzato@e-distribuzione.com (F.C.); \\ marco.diclerico@e-distribuzione.com (M.D.C.); simone.ferrero@e-distribuzione.com (S.F.) \\ 2 DIAEE-Department of Astronautics, Energy and Electrical Engineering, University of Rome Sapienza, \\ 00184 Rome, Italy; marco94vivian@gmail.com \\ * Correspondence: mariacarmen.falvo@uniroma1.it
}

Received: 22 January 2020; Accepted: 18 February 2020; Published: 20 February 2020

\begin{abstract}
Electric Vehicles (EVs) are becoming one of the main answers to the decarbonization of the transport sector and Renewable Energy Sources (RES) to the decarbonization of the electricity production sector. Nevertheless, their impact on the electric grids cannot be neglected. New paradigms for the management of the grids where they are connected, which are typically distribution grids in Medium Voltage (MV) and Low Voltage (LV), are necessary. A reform of dispatching rules, including the management of distribution grids and the resources there connected, is in progress in Europe. In this paper, a new paradigm linked to the design of reform is proposed and then tested, in reference to a real distribution grid, operated by the main Italian Distribution System Operator (DSO), e-distribuzione. First, in reference to suitable future scenarios of spread of RES-based power plants and EVs charging stations (EVCS), using Power Flow (PF) models, a check of the operation of the distribution grid, in reference to the usual rules of management, is made. Second, a new dispatching model, involving DSO and the resources connected to its grids, is tested, using an Optimal Power Flow (OPF) algorithm. Results show that the new paradigm of dispatching can effectively be useful for preventing some operation problems of the distribution grids.
\end{abstract}

Keywords: Dispatching Service; Dispersed Generation; Distribution Grid; Electrical Vehicle; Optimal Power Flow; Power Flow; Power System; Simulation Models

\section{Introduction}

Stopping climate change requires a revolution in the way we produce and consume energy. On the production side, the most important step is to reduce the generation from carbon and other fossil fuel to near-zero, and to increase the amount of the Renewable Energy Sources (RES). On the consumption side, the revolution requires an improvement of the efficiency and in the electrification of the energy demand. In the transport sector, these two objectives can be reached thanks to the spread of Electric Vehicles (EVs), whose Charging Stations (EVCS) power is enhancing (up to $250 \mathrm{~kW}$ ) to allow a faster recharge [1-4]. All these changes affects the operation of the power systems, at transmission grids level in High Voltage (HV) and distribution grids level in Medium Voltage (MV) and Low Voltage (LV) $[5,6]$. The issues are different in the two stages of the power system: most of the RES-based power plants are connected to the distribution grids (Dispersed Generation, DG) and all the EVCS are connected to the distribution grids, thus, the first impact is on the distribution level. However, at the same time, the DG, typically RES-based, also has indirect impacts on the transmission level. some problems related to the operation of the transmission grids, due to the DG, are: 
- $\quad$ Reduction of the equivalent load on the HV grid, with reactive power management problems in light-load hours and thus high voltage problem;

- $\quad$ Reduction or turning off of conventional power plants generation, reducing the reserves for the control of the whole power system, and in particular causing a reduction of the inertia and of the spinning reserve and thus frequency control issues,

- Inverse power flows on the primary substations in some hours,

- Dispatching reserves and rules for controlling the frequency, inappropriate for the reliability of the grid, increasing costs of the dispatching service for the Transmission System Operators (TSOs).

On the other hand, some problems related to the operation of the distribution grid, due to DG and EVCS are:

- Congestions on some branches,

- Voltage drops and critical voltage control,

- Inverse power flows on some lines through the primary substations,

- Increasing of the power losses,

- $\quad$ Power quality issues.

Many of the listed issues are due to the fact that the RES-based DG and EVCS are still managed with a "fit and forget" approach: the amount of electricity available in production or needed in consumption is put into or delivered by the system, without any limits. This type of approach is no longer feasible, especially when the rate of DG and EVs become high, as is the case in Europe.

A solution of most of the listed issues could be an active management of distribution grids and of the sources, there connected, in charge to the Distributor System Operators (DSOs), similar to the management done by the TSOs with the HV grids. For all these reasons, a reform of the electrical dispatching is in progress in Europe, including Italy [7]. The common objective of the review process in all the European Countries is to test new ways for getting the necessary resources to guarantee the reliability of the whole power system, through a new form of dispatching service. It also includes taking in new entities, such as DG, MV and LV flexible end-users (such as EVCS) and their combinations, and thus involving in the dispatching functions the DSOs.

In literature, many recent works are present on the impact on the transmission and distribution grids of RES-based DG and EVCS. Some paper are dedicated only to the impacts and possible management solution for the RES-based DG on the distribution grids [8-11]. Others are related only to the influence and possible control strategies of EVCS, in distribution grids, according to a Vehicle-to-Grid approach, in reference to a smart grid environment [11-21]. Other papers are dedicated to analyze the combination of the effect of the two (DG and EVCS) and of their suitable management in the distribution grids operation and planning [22-25]. Few papers deal with the problems related both to the distribution and transmission grids, linked to the DG and EVCS [26,27].

In this context, the originality of the present work is to propose and test a new dispatching model on a real distribution system, in line with the reform that is in progress in Europe and in Italy [7], that implies a smart management of EVCSs, coordinated with DG, mainly RES-based. Analyses and simulations are done on the new model in reference to a real distribution system, in reference to future scenarios (2030), owned and operated by the most important DSO in Italy, e-distribuzione.

The work is so organized. Section 2 includes a short description of new dispatching models proposed by the reform in progress. The main features of the real grid object of the analysis are in Section 3. Section 4 shows the methodologies and the assumptions for the simulations. Section 5 describes and discusses the obtained results. In Section 6, conclusions are drawn.

\section{Dispatching Models in the European Reform}

The Italian TSO (TERNA) is moving forward in the dispatching reform guided by the Italian Authority for electricity (ARERA) in accordance with the European policies and rules [7]. In 2013, the 
debate concerning new dispatch models started. The investigation was through three possible models managing the dispatching sources that exploit RES-based generators, which can be summarized as follows:

- Model 1, called "Extended Central Dispatching": all the sources connected to the transmission and distribution grids, including generators and flexible end-users, must provide dispatching services to the TSO, through the ancillary service market, and only local system services to the DSO for solving grid problems at distribution level, with a direct call.

- Model 2, called "DSO Local Dispatching": the TSO can purchase system services from traditional generation power plants, RES-based power plants or flexible end-users connected to the High Voltage (HV) grids, and directly from DSO, through the ancillary service market. The DSO itself can indeed purchase dispatching services or local system services, from the DG and flexible end-users, connected to its medium voltage (MV) and low voltage (LV) grids, through a new ancillary service market at distribution level.

- Model 3, called "Planned Profile Exchange at HV/MV Electrical Substation (ESS)": all the sources connected to the transmission grids, including generators and flexible end-users, must provide dispatching services to the TSO. The DSO is responsible only for the planned energy exchange in a single primary ESS, or in a zone that includes several primary ESS, but it does not provide any dispatching service to the TSO. This profile is guaranteed by DSO, using the DG and flexible end-users, connected to its MV and LV grids; they can be also called for system services on the distribution grids with a direct call by DSO.

Nowadays the reforms are heading toward Model 1, where the TSO can directly draw new dispatching sources from entities connected to the distribution system. The requests of the TSO do not consider the issues that may arise in the distribution grids, such as congestions, under-voltage and over-voltage phenomena and so on; thus, the DSOs are not only suffering the unavoidable spread of DG, but also an external control, which may lead to further problems. The control of the DG and of the flexible loads, by the DSO over its system, could be the best solution to avoid technical issues (Model 2 or 3). In the meantime, to guarantee a predictable exchange profile at primary ESS, reducing the global dispatching cost could be easy in this case for the DSO and could be useful for TSO (Model 3). Obviously, this can be done in a smart grid, where suitable communication [15] and control technologies are available between the DSO and the dispersed resources. This is the reason why the most important Italian DSO, e-distribuzione, is investigating the opportunity to apply Model 2 or 3 instead of Model 1, which is currently tested by the Italian TSO.

\section{E-Distribuzione Test Case}

The study has been carried out on a real distribution grid belonging to $e$-distribuzione, which is the most important DSO in Italy, and is involved in many studies on the impact of EVCS and DG on distribution grids [28-32]. The main features of the distribution grid are summarized in Figure 1. 


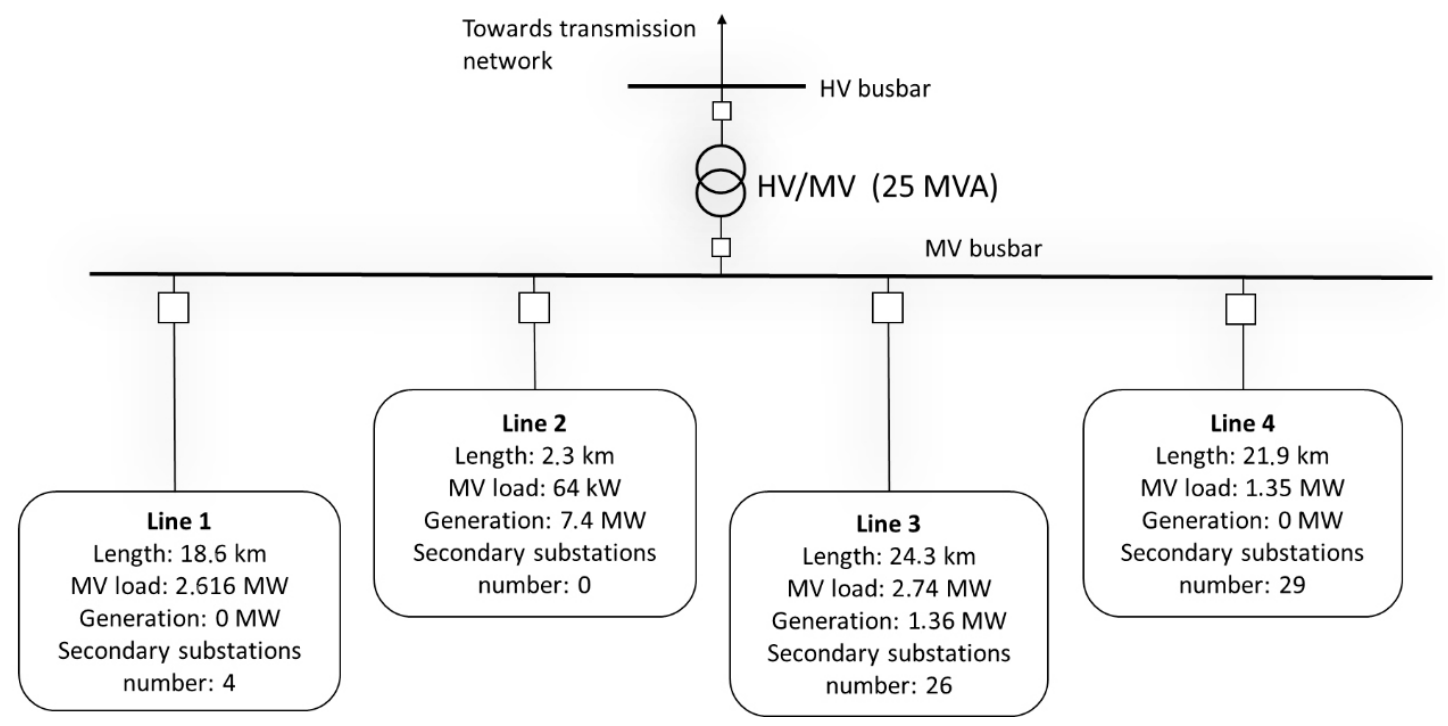

Figure 1. e-distribuzione distribution grid.

The system is located in Southern Italy and it is subtended to a primary Electrical Sub-station (ESS) with a 25 MVA power transformer and includes four lines. The main data on the lines are summarized in Table 1.

Table 1. MV lines characteristics.

\begin{tabular}{ccccc}
\hline Line & Length $[\mathbf{k m}]$ & $\begin{array}{c}\text { \% in Overhead } \\
\text { Line Naked }\end{array}$ & \% in Underground & $\begin{array}{c}\text { \% in Overhead } \\
\text { Line Insulated }\end{array}$ \\
\hline 1 & 18.6 & $59 \%$ & $0 \%$ & $41 \%$ \\
2 & 2.3 & $0 \%$ & $0 \%$ & $100 \%$ \\
3 & 24.3 & $1 \%$ & $0 \%$ & $99 \%$ \\
4 & 21.9 & $85 \%$ & $4 \%$ & $11 \%$ \\
Tot & 67.1 & $45 \%$ & $1 \%$ & $54 \%$ \\
\hline
\end{tabular}

All the MV generators are Photovoltaic (PV) systems with a total peak power of 8.76 MW. The powers and the lines to which they are connected are detailed in Table 2.

Table 2. MV PV Generators.

\begin{tabular}{ccc}
\hline MV Generation Plants & Power $[\mathbf{k W}]$ & Line \\
\hline G1 & 7983 & 2 \\
G2 & 48 & 3 \\
G3 & 1250 & 3 \\
G4 & 60 & 3 \\
\hline
\end{tabular}

Big consumers connected directly to MV lines are detailed in Table 3 with their available power and delivery line.

For each passive customer (industrial and residential) in MV, e-distribuzione has provided data about the active and reactive power profile in time, every $15 \mathrm{~min}$, in reference to the four seasons and the two typical days of the week (workdays and weekends). The LV loads and generators are represented, in their respective secondary ESS, as aggregate profiles of active and reactive power, because the information about the LV network are not given. The production profile of the PV systems have been calculated in reference to the irradiation values in the analyzed area through System Advisor Model (SAM) software [33,34]. In addition, e-distribuzione provides the technical features of the MV grid components. 
All these data, useful for the simulations, are not reported here, both for lack of space and privacy policies.

Table 3. MV passive customers.

\begin{tabular}{ccc}
\hline MV Customers & Power $[\mathbf{k W}]$ & Line \\
\hline C1 & 20 & 3 \\
C2 & 550 & 3 \\
C3 & 350 & 4 \\
C4 & 64 & 2 \\
C5 & 500 & 4 \\
C6 & 866 & 1 \\
C7 & 505 & 4 \\
C8 & 501 & 1 \\
C9 & 567 & 1 \\
C10 & 682 & 1 \\
C11 & 300 & 3 \\
C12 & 120 & 3 \\
C13 & 250 & 3 \\
C14 & 1500 & 3 \\
TOT & 6775 & - \\
\hline
\end{tabular}

\section{Models for Simulations}

The system has been implemented in a MATLAB environment and simulated through MATPOWER Power Flow (PF) and Optimal Power Flow (OPF) algorithms [35,36]. Twelve simulations have been analyzed according to season and the day of the week was considered. The PF and OPF run every $15 \mathrm{~min}$. The simulations take into account only the active powers as control variables, because it is assumed to be a dispatching model that deals only with the control of the active power of the sources involved with a different objective, according to the reform proposals in progress in Europe and in Italy.

A first PF analysis in the present scenario was performed, to check the operation of the grid in the present and without any type of dispatching action implemented. The results show that the peak demand is reached during the summer evening. Nevertheless, the grid constraints, such as voltage and current limits, are widely respected all year long and the grid turns out to be discharged and highly suitable for new sources integration.

\subsection{Assumptions for Simulations}

An evaluation was carried out about possible future scenarios in 2030 considering the targets imposed by the European Commission and Italian Authority [1-3]. The future scenarios have been chosen based on the experience on the field of e-distribuzione authors and their expertise coming out by the management and operation of the Italian distribution grid [28]. It is well known that the forecasts are dependent on many different factors, such as investments, policies and politics of the selected nation. For these reasons, three different scenarios have been deduced according to the speed of the growth, as shown in Table 4.

Table 4. Percentage of growth for 2030.

\begin{tabular}{cccc}
\hline \multirow{2}{*}{ Growth } & PV Increase at LV Level & PV Share at MV Level & EVs Share \\
\cline { 2 - 4 } & {$[\%]$} & {$[\%]$} & {$[\%]$} \\
\hline Slow & +100 & 50 & 10 \\
\hline Moderate & +150 & 70 & 12 \\
Fast & +200 & 90 & 15 \\
\hline
\end{tabular}


Since $31 \mathrm{GW}$ of PV power has to be installed at distribution level to reach $51 \mathrm{GW}$, for the LV size, the installed power of domestic PV plants should at least double and in the fast growth scenario, it should triple. Thus, the variation will be considered within 100 and 200\%. Concerning the PV installed at $\mathrm{MV}$, the current plants are left as they are, while new PV plants are supposed to rise in the proximity of the MV customers, affecting between $50 \%$ and $90 \%$ of them. Most of the studies highlight a sudden boom in the sale of EV between 2020 and 2025, when the technology would be mature to be worldwide adopted. Unfortunately, nowadays, Italy holds one of the last positions in the European ranking of EV readiness, hence, the forecasts are discouraging; even in the best scenario the percentage goal to contain the emission is not achieved. The Italian percentages of EV share in 2030 according to e-distribuzione fluctuate between 10 and $15 \%$.

The integrated EVCSs are assumed to be:

- Home station, with a rated power of $7.2 \mathrm{~kW}$;

- Pole station, with a rated power of $22 \mathrm{~kW}$;

- $\quad$ Super-fast station, with a rated power of $350 \mathrm{~kW}+2150 \mathrm{Kw}$;

The number of every kind of EVCS is proportional to the EVs share and the number of vehicles circulating in the area, but it is obtained following different methodologies and considering a battery capacity of $80 \mathrm{kWh}$. It is worth to note that the study is focused on how the distribution grid could be affected by the increase of installed PV power, EVCSs and their management. Thus, any kind of technical information, such as kind of socket connection, details of the recharge and battery properties, is avoided, because they do not concern this dissertation.

From the DSO point of view, the EVCS could be seen as a flexible load. Indeed, the charging stations can not only withdraw energy from the grid, as is pretty much common today, but they will be able to inject power, as is shown in many pilot projects, with so-called Vehicle to Grid (V2G) technology [13-21]. In this framework, an assumption for simulations is to consider that $25 \%$ of the batteries are not accessible, because they need to be charged.

\subsection{OPF Objetive Functions}

In reference to these scenarios and assumptions, different OPF analyses have been performed in reference to different objective function. In particular, to minimize the losses, to get a peak shaving function and to get a voltage drop containment.

The higher the power crossing the primary ESS, the higher are the losses in the system, and consequently, the operation cost. This is the reason why the DSOs are often concerned about the minimization of the active power flow in the primary ESS. The peak shaving concept lies on the assumption that some loads or generator can be shifted in time to avoid high losses on the grid. Any storage available in the grid could be a source to fulfil this need, since it can inject and withdraw energy whenever it is needed, respecting the capacity and maximum power constraints. The batteries of the EV connected to the distribution grid can be a useful storage for this task. In particular, the peak shaving corresponds to an energy injection (or withdraw in case of negative peak) that has to be withdrawn (or injected) within the day to allow the daily cycle of an EV battery. The proposed EV battery cycle considers that the EV drivers change the range setting of the lower limit of the State of Charge (SOC) to $50 \%$. Furthermore, the hypothetic daily trip ( $9 \%$ of discharge) is divided into the route from home to office and vice versa (Figure 2). 


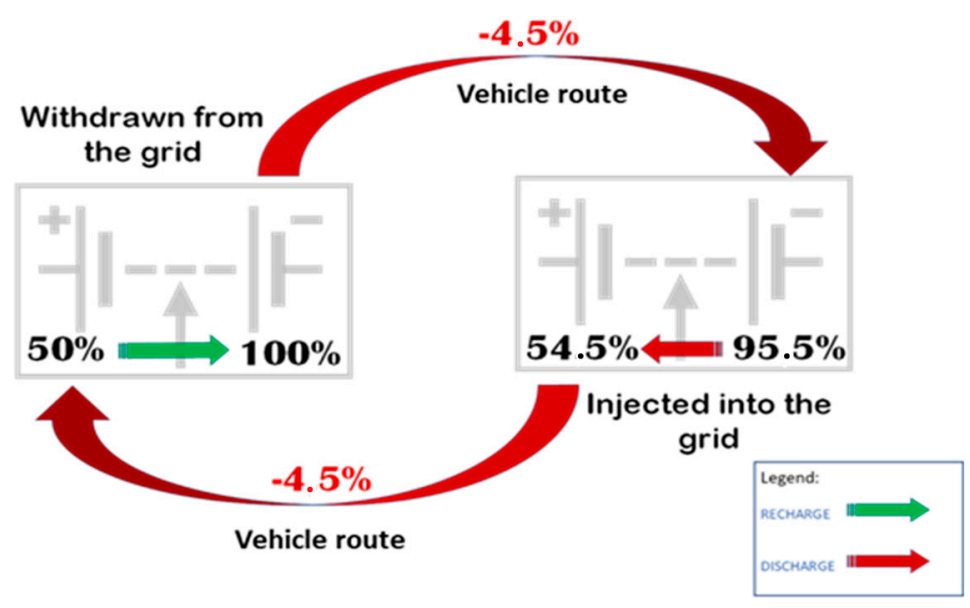

Figure 2. EV battery cycle of use hypnotized in the simulations.

The energy injected to the grid has to be the $82 \%$ of the energy withdrawn during the day to have a perfect charging cycle. The energy spent during the route is seen as a loss from the grid point of view, but it is in fact the energy that makes the EVs move, thus, the most useful from the driver's point of view. Two algorithms have been carried on with two different primary goals: to reduce the evening peak and to reduce the reverse power flow. These two purposes cannot be completely decoupled from each other; indeed, as an EV battery is going to be discharge in the evening, it will unavoidably recharge during the day, flatting the negative peak and vice versa. The goal of the analysis is to evaluate the power, the energy and the percentage of EVs involved guaranteeing a given peak shaving service. This evaluation of peak shaving potential is based on thresholds that limit the positive active power, which can flow through the primary ESS; once this limit is broken, the algorithm is set to exploit the charging station to balance the grid. The evening peak set point is $4.7 \mathrm{MW}$, because it allows a realistic exploitation of the EVs batteries without requiring more power than the available one. The minimum active power threshold is set to $-2.7 \mathrm{MW}$.

As the voltage drop is remarkable during summer evening, the home stations are programmed to inject power to the grid when violation occurs. An important assumption is made: the stations belong to the DSO or the EVs users are inclined to accept less power availability, the available power indeed can be modified to provide local services, only if there is a will from the battery side. The percentage of the availability of the battery to be charged or discharged and the presence of the vehicles have been considered equal to $45 \%$ of the total installed power. This analysis aims to verify whether the defined percentage of dispatchable power can guarantee the containment of the voltage drop within $\pm 6.3 \%$.

\section{Results and Discussion}

\subsection{PF Analysis}

A first PF analysis has been made in reference to the future scenarios, for checking the performance of the grid, without any dispatching model implemented. The results are here reported in reference to the case more stressing, which is the one for the fast growth scenario in spring and summer. The impact of increased PV systems, home stations and pole stations on the grid in terms of active power at the MV bus-bar is shown, for the fast growth scenario, in Figure 3a for the spring season and in Figure $3 \mathrm{~b}$ for the summer season, compared to the real profile of nowadays. It is evident that the presence of the EVCS has as results an increasing of the amount of active power at MV bus-bar, only during evening hours, linked to the evening use of the home stations. During the noon hours, the prevalent effect is of increasing of the negative active power at MV bus-bar (up to $5 \mathrm{MW}$ ), due to the higher production by new PV plants. 


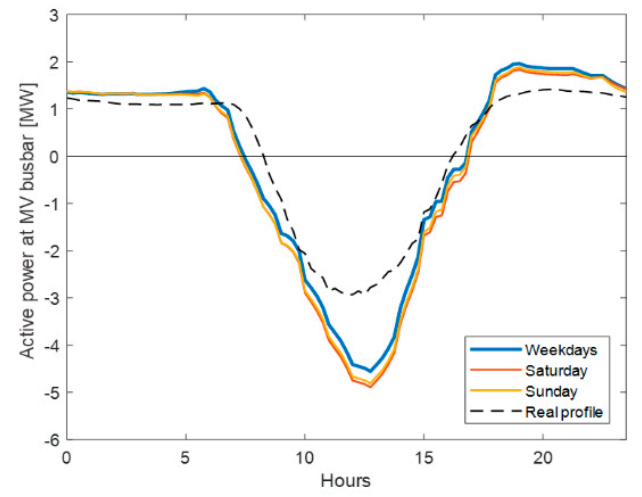

(a)

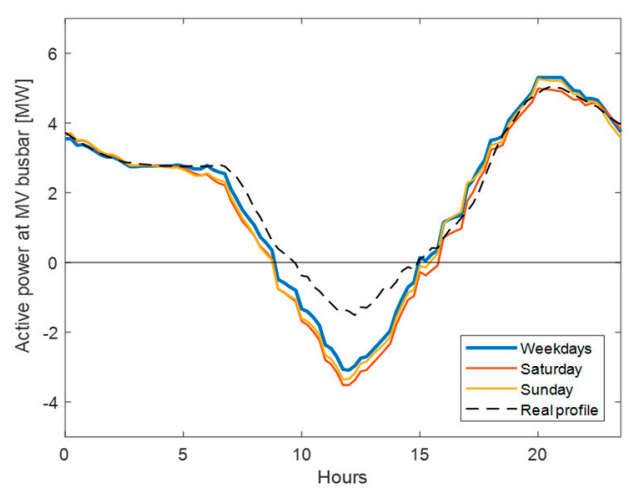

(b)

Figure 3. Active power at MV side of the primary ESS for fast growth scenario during spring (a) and summer (b) considering the impact of Home stations and pole stations.

Figure 4 shows the trend of the active power in the primary ESS adding also the super-fast EVCS, which could require up to $750 \mathrm{~kW}$, during spring season (a) and summer season (b). The effect is the same described for the case in Figure 3.

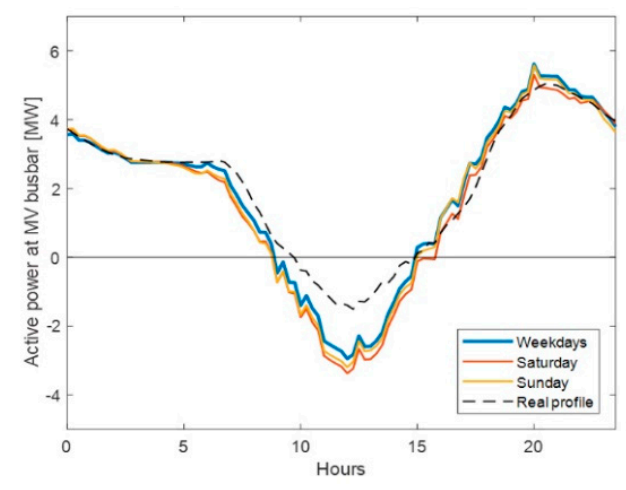

(a)

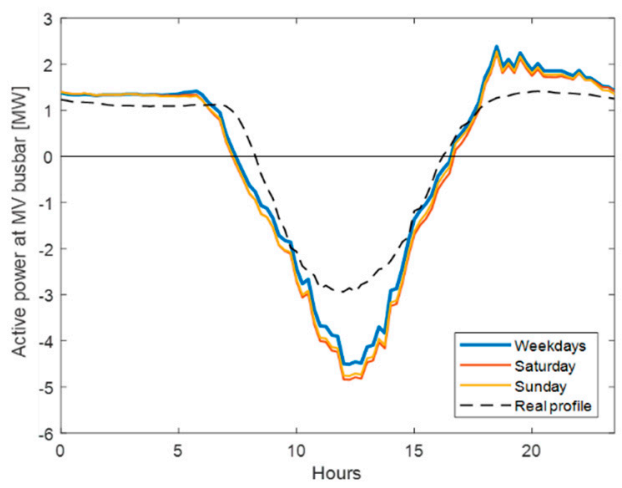

(b)

Figure 4. Active power at MV side of the primary ESS for fast growth scenario during spring (a) and summer (b) considering the impact of Home stations, pole stations and super-fast stations.

From the simulation results, the voltage was also checked: a drop of $6.71 \%$ was tested during summer, but it was confined within $5 \%$ during the rest of the year. Nevertheless, the grid still did not experience any congestion and it is highly suitable for further installations.

\subsection{OPF Analysis In Case Of Evening Peak Shaving Service}

The most interesting scenario analyzed is the most stressful, that is, the fast growth one during a summer weekday. A threshold assumed to be of $4.7 \mathrm{MW}$ implicates an energy injection of $760 \mathrm{kWh}$, which stands for an exploitation of 29 home stations more than the foreseen ones. The peak power indeed reaches $800 \mathrm{~kW}$ (Figure 5), which means a contemporary recharge of about 111 EVs. The recharges consider the energy spent for the daily trip and they occur during the rest of the day, preferably during the time of reverse power flow. The 111 vehicles are $60 \%$ of the total EVs fleet, but $79 \%$ of the available EVs. 


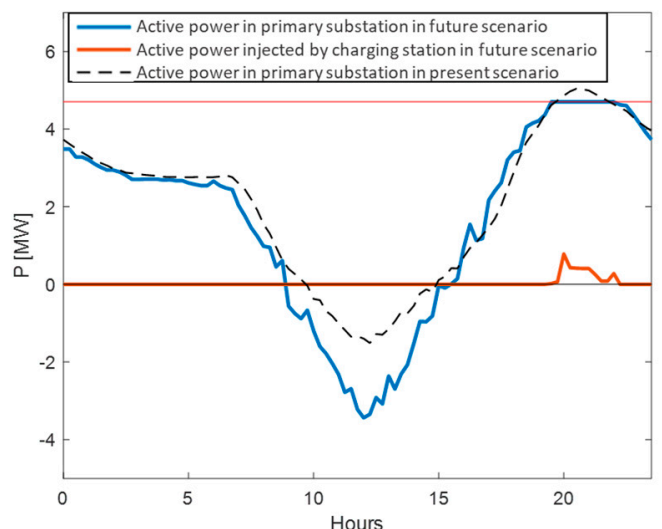

(a)

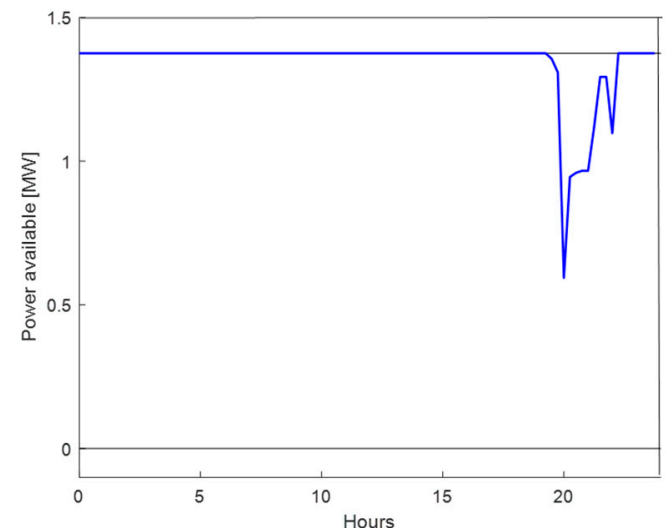

(b)

Figure 5. Active power at the MV side of the primary ESS and power injected by the EV home stations for the evening peak shaving (a); power available by the home stations (b).

\subsection{OPF Analysis In Case Of Reverse Power Flow Shaving}

From the energy point of view, the system will need to charge $22 \mathrm{EVs}$ more to increase the energy demand of $880 \mathrm{kWh}$. On the other hand, $949 \mathrm{~kW}$ of peak power (Figure 6) requires 21 EVCS more, with the strong assumption that they are used at the same time. In this case, the peak power dictates the right spread of EVs which is equal to $49 \%$. Nevertheless, this percentage is not actually a needed condition for the right functioning of the system, it should need just 42 EVs plugged at the same time. The recharge implies the discharge of part of the battery during the evening; this helps to smooth out the peak power and the voltage.

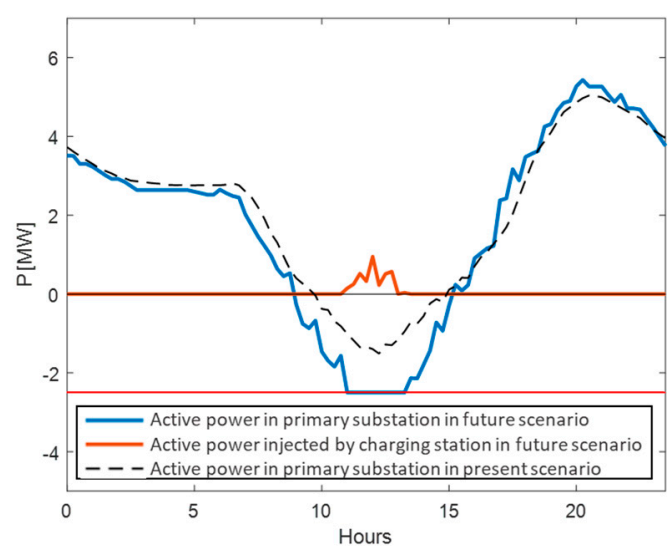

(a)

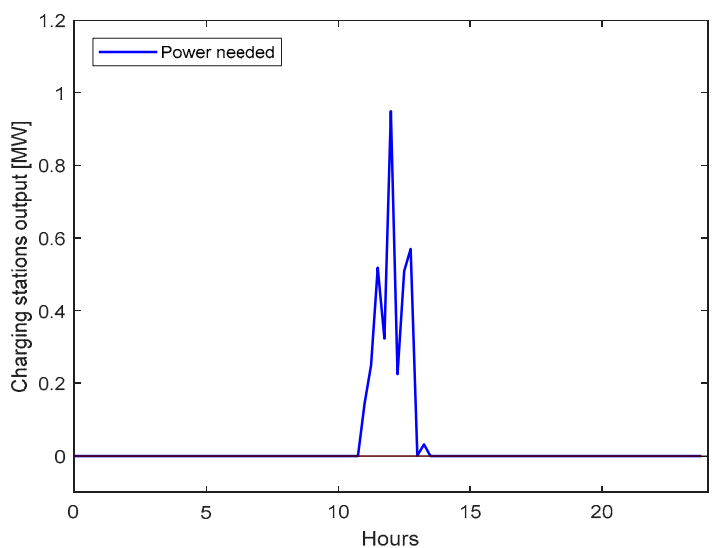

(b)

Figure 6. Active power at MV side of the primary ESS and power injected by the EV pole station for the reverse power flow shaving (a); power withdrawn by the EV pole stations (b).

Table 5 shows the results of the peak shaving analysis: the power and energy required by the DSO vary according to the goal set. The EV drivers' awareness is calculated as the number of EV drivers that allow the grid to use their own battery over the total number of EV drivers in the area. The easier objective to implement appears to be the noon negative peak shaving, which requires only $22 \%$ of drivers' awareness. Nevertheless, this solution implies that installing 21 EVCS is too many compared to the circulating fleet (420 more EVs should be bought). 
Table 5. Power and energy required for peak shaving services.

\begin{tabular}{ccccccc}
\hline Goal & Set-Point & \multicolumn{2}{c}{ Withdrawal } & \multicolumn{2}{c}{ Injection } & EV Drivers Awareness \\
\hline \multirow{2}{*}{ Evening peak shaving } & \multirow{2}{*}{$4.7 \mathrm{MW}$} & 926 & $\mathrm{kWh}$ & 760 & $\mathrm{kWh}$ & $60 \%$ \\
& & - & $\mathrm{kW}$ & 800 & $\mathrm{~kW}$ & \\
\multirow{2}{*}{ Noon negative peak shaving } & $-2.7 \mathrm{MW}$ & 880 & $\mathrm{kWh}$ & 721 & $\mathrm{kWh}$ & $22 \%$ \\
\hline
\end{tabular}

The noon shaving goal instead could be reach without any economic effort; it simply depends on the EVS drivers' availability, which should reach a quite high percentage.

\subsection{OPF Analysis In Case Of Voltage Drop Containment}

The active power through the primary ESS has not changed a lot, except for the evening peak between $8 \mathrm{pm}$ and $10 \mathrm{pm}$, when the home stations inject active power to compensate the voltage violation (Figure 7). The home stations are indeed the only source that can be exploited because it is the only one available during those hours.

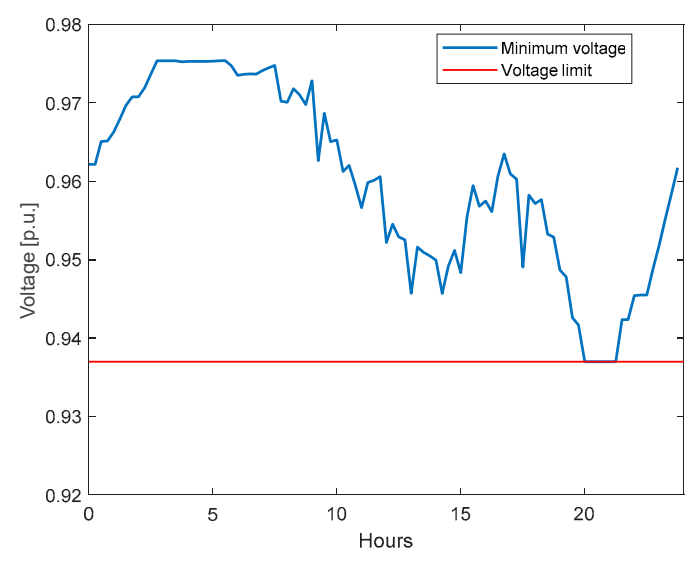

(a)

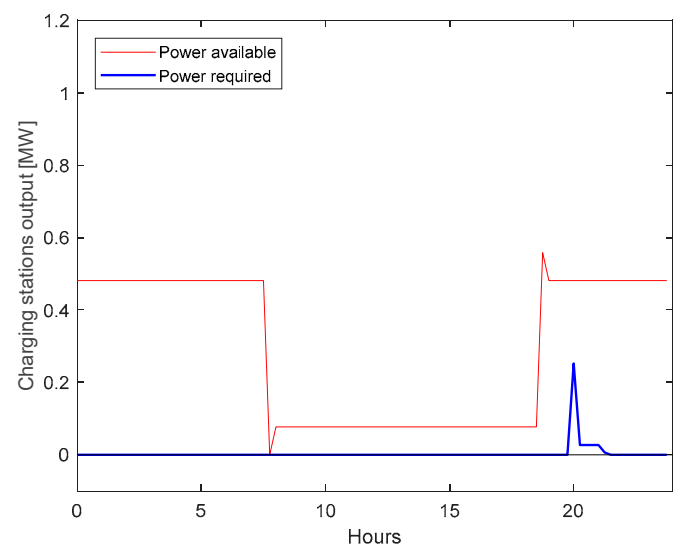

(b)

Figure 7. Profile of the minimum voltage in the whole network (a); power injected by the EVs home station to contain the voltage violation $(\mathbf{b})$.

The total power requested by the grid is $273 \mathrm{~kW}$, thus, $57 \%$ of the total dispatchable power. The violation is highly contained within the threshold; this scenario requires only 37 available EVs batteries for a total of $160 \mathrm{kWh}$. The energy needed is much lower than the one that the involved EVs can provide; thus, the reduction of energy in each car will be almost derisory.

\section{Conclusions}

A new paradigm for the management of distribution grids, with big amount of EVCS and RES-based DG, is investigated in reference to a real distribution grid, belonging to the main Italian DSO, e-distribuzione. First, in reference to future scenarios of spread of RES-based power plants and EVCS, some PF analyses have been made to check the performance of the distribution grid in reference to the usual operation. Second, considering a new dispatching model involving DSO and EVCS, the opportunity to provide different local and system services are tested, using OPF algorithms.

The impact of EVCS and DG power growth, in 2030, is modelled and simulated in MATLAB environment, for three future scenarios, according to the intensity of the diffusion. After running a first PF simulation, the network detected a high peak power, given by the evening loads and a negative peak power provided by the DG plants. Thus, with OPF algorithms, the flexible management of the installed EVCS for providing services to the DSO was tested. The first algorithm was intended to cut off the voltage violations that occur if the voltage limits are at $\pm 6.3 \%$, as local service. The OPF algorithm tends 
to maximize the available power at the EVCS and acts only if a violation occurs. The study proved that it is possible to successfully contain the voltage drop within $6.3 \%$, assuming an EVs availability of $45 \%$. Another OPF algorithm had the goal to restrict the active power flow in the primary ESS within an upper and lower limit. This is effectively done to lessen the grid losses and provides a given value of maximum input/output power to the transmission grid, as system service. The tests have shown that the availability of EVs drivers to provide this kind of services is fundamental rather than high spread of EVs. In general, all the results show that the proposed paradigm of dispatching involving DSO and their resources (EVCS and DG) can effectively improve the distribution grid performance, to prevent its operation problems (such as under-voltages or congestions) and to support the whole power system management with system services.

Author Contributions: Conceptualization, M.C.F., F.C., M.D.C.; methodology, M.V., M.D.C. and S.F.; software, M.V.; validation, M.V., M.D.C. and S.F.; formal analysis, M.V. and M.C.F.; investigation, M.V.; resources, M.V. and M.C.F.; data curation, M.V., M.D.C. and S.F.; writing-original draft preparation, M.V.; writing, review and editing, M.V. and M.C.F.; visualization, M.V.; supervision, M.C.F. and F.C.; project administration, M.C.F. and F.C. All authors have read and agreed to the published version of the manuscript.

Funding: This research received no external funding.

Conflicts of Interest: The authors declare no conflict of interest. The funders had no role in the design of the study; in the collection, analyses, or interpretation of data; in the writing of the manuscript, or in the decision to publish the results.

\section{References}

1. International Energy Agency. Global EV Outlook 2019. Technical Report. 2019. Available online: https://webstore.iea.org/download/direct/2807?fileName=Global_EV_Outlook_2019.pdf (accessed on 14 November 2019).

2. European Commission. Communication from the Commission to the European Parliament, the Council, the European Economic and Social Committee and the Committee of the Regions; A Policy Framework for Climate and Energy in the Period from 2020 to 2030. 2014. Available online: https://eur-lex.europa.eu/legalcontent/EN/ALL/?uri=CELEX\%3A52014DC0015 (accessed on 19 February 2020).

3. MISE, Italian Minister Ministry of Economic Development. Proposta di Piano Nazionale Integrato per L'energia e il Clima. 2018; p. 46. Available online: https://www.mise.gov.it/images/stories/documenti/Proposta_di_Piano_ Nazionale_Integrato_per_Energia_e_il_Clima_Italiano.pdf (accessed on 19 February 2020).

4. Transport \& Environment. Electric Surge: Carmakers' Electric Car Plans across Europe 2019-2025. 2019, p. 30. Available online: https://www.transportenvironment.org/sites/te/files/publications/2019_07_TE_electric_ cars_report_final.pdf (accessed on 19 February 2020).

5. U.S. Department of Energy, Office of Electricity Delivery \& Energy Reliability. Modern Distribution Grid: Advanced Technology Maturity Assessment. 2017. Available online: https://gridarchitecture.pnnl.gov/ modern-grid-distribution-project.aspx (accessed on 19 February 2020).

6. Vijay, A.; Fouquet, N.; Staffell, I.; Hawkes, A. The value of electricity and reserve services in low carbon electricity systems. Appl. Energy 2017, 113, 111-123. [CrossRef]

7. ARERA. Italian Autorithy for Energy and Environment. 393/2015/R/eel-Riforma Organica Della Regolazione del Servizio di Dispacciamento Dell'energia Elettrica e Conseguente Attivazione del Progetto Interdirezionale RDE (Riforma del Dispacciamento Elettrico). 2015. Available online: https:/www.arera.it/allegati/docs/15/ 393-15.pdf (accessed on 19 February 2020).

8. Liang, X. Emerging Power Quality Challenges Due to Integration of Renewable Energy Sources. IEEE Trans. Ind. Appl. 2017, 53, 855-866. [CrossRef]

9. Paduchuri, C.B.; Dash, S.S.; Bayındır, R.; Behera, R.K.; Subramani, C. Analysis and experimental investigation for grid-connected $10 \mathrm{~kW}$ solar PV system in distribution networks. In Proceedings of the 2016 IEEE International Conference on Renewable Energy Research and Applications (ICRERA), Birmingham, UK, 20-23 November 2016.

10. Tamura, J.; Kondo, K.; Baba, J. Study of the LFC Signal Dispatching Method to Compensate Short Period Power Fluctuation by Use of Many Photovoltaics. In Proceedings of the 2018 IEEE PES Asia-Pacific Power and Energy Engineering Conference (APPEEC), Kota Kinabalu, Malaysia, 7-10 October 2018; pp. 1-6. 
11. Dreidy, M.; Mokhlis, H.; Mekhilef, S. Inertia response and frequency control techniques for renewable energy sources: A review. Renew. Sustain. Energy Rev. 2017, 69, 144-155. [CrossRef]

12. Boudina, R.; Wang, J.; Benbouzid, M.; Khoucha, F.; Boudour, M. Impact evaluation of large-scale integration of electric vehicles on power grid. Front. Energy. 2017. [CrossRef]

13. Omran, N.G.; Filizadeh, S. A semi-cooperative decentralized scheduling scheme for plug-in electric vehicle charging demand. Int. J. Electr. Power Energy Syst. 2017, 88, 119-132. [CrossRef]

14. Min, Z.; Qiuyu, C.; Jiajia, X.; Weiwei, Y.; Shu, N. Study on influence of large-scale electric vehicle charging and discharging load on distribution system. In Proceedings of the 2016 China International Conference on Electricity Distribution (CICED), Xi'an, China, 10-13 August 2016; pp. 1-4.

15. Qiao, Z.; Yang, J. Low-voltage distribution network reconfiguration considering high penetration of electric vehicles: A UK case study. In Proceedings of the 2016 IEEE International Conference on Renewable Energy Research and Applications (ICRERA), Birmingham, UK, 20-23 November 2016.

16. Turker, H.; Pirsan, V.; Bacha, S.; Frey, D.; Richer, J.; Lebrusq, P. Heuristic strategy for smart charging of Plug-In Electric Vehicle in residential areas: Variable charge power. In Proceedings of the 2014 International Conference on Renewable Energy Research and Application (ICRERA), Milwaukee, WI, USA, 19-22 October 2014; pp. 938-944.

17. Gaur, P.; Soren, N.; Bhowmik, D. Impact Assessment of Vehicle-to-grid Technology in LFC of Multi-area Solar-thermal Power System. IJRER 2018, 8, 1580-1590.

18. Brusaglino, G. Integration of road electric vehicles into the smart grid system. In Proceedings of the 2013 International Conference on Clean Electrical Power (ICCEP), Alghero, Italy, 1-13 June 2013; pp. 177-182.

19. Vinayak, P.; Sindhu, M. An intelligent control strategy for vehicle-to-grid and grid-to vehicle energy transfer. In Proceedings of the First International Conference on Materials Science and Manufacturing Technology, Tamil Nadu, India, 12-13 April 2019.

20. Eajal, A.A.; Shaaban, M.F.; El-Saadany, E.F.; Ponnambalam, K. Fuzzy logic-based charging strategy for Electric Vehicles plugged into a smart grid. In Proceedings of the 2015 IEEE International Conference on Smart Energy Grid Engineering (SEGE), Oshawa, ON, Canada, 17-19 August 2015; pp. 1-6.

21. Chukwu, U.C.; Mahajan, S.M. Modeling of V2G net energy injection into the grid. In Proceedings of the 2017 6th International Conference on Clean Electrical Power (ICCEP), Santa Margherita Ligure, Italy, 27-29 June 2017.

22. Rodriguez-Calvo, A.; Cossent, R.; Frias, P. Integration of PV and EVs in unbalanced residential LV networks and implications for the smart grid and advanced metering infrastructure deployment. Int. J. Electr. Power Energy Syst. 2017, 91, 121-134. [CrossRef]

23. Ahmadian, A.; Sedghi, M.; Aliakbar-Golkar, M. Fuzzy Load Modeling of Plug-in Electric Vehicles for Optimal Storage and DG Planning in Active Distribution Network. IEEE Trans. Veh. Technol. 2016, 66, 99. [CrossRef]

24. Coninx, K.; Moradzadeh, M.; Holvoet, T. Combining DSM and Storage to Alleviate Current Congestion in Distribution Grids. In Proceedings of the 2016 IEEE PES Innovative Smart Grid Technologies Conference Europe (ISGT-Europe), Ljubljana, Slovenia, 9-12 October 2016; pp. 1-2.

25. Masotti, L.; Dolara, A.; Leva, S. Vehicle-to-Grid for peak shaving in a Medium Voltage Grid with PV plants. In Proceedings of the 2019 International Conference on Clean Electrical Power (ICCEP), Otranto, Italy, 2-4 July 2019.

26. Hadush, S.Y.; Meeus, L. DSO-TSO cooperation issues and solutions for distribution grid congestion management. Energy Policy 2018, 120, 610-621. [CrossRef]

27. Shashank, N.G.; Tianyang, Z.; Choung, J.K.; Rajit, G. Transmission, Distribution deferral and Congestion relief services by Electric Vehicles. In Proceedings of the 2019 IEEE Power \& Energy Society Innovative Smart Grid Technologies Conference (ISGT), Washington, DC, USA, 18-21 February 2019.

28. Di Clerico, M.; Cazzato, F.; Di Martino, D.; Marmeggi, F. The increase of distributed generation on Enel Distribuzione's network: State of the art, actions and strategies for integration. In Integration of Renewables into the Distribution Grid. In Proceedings of the CIRED 2012 Workshop: Integration of Renewables into the Distribution Grid, Lisbon, Portugal, 29-30 May 2012; pp. 1-4.

29. Di Clerico, M.; Caneponi, G.; Cazzato, F.; Cochi, S.; Falvo, M.C.; Manganelli, M. EVs Charging Stations in Active Distribution Grids: A Real Case-Study of Smart Integration. In Proceedings of the 2016 International Symposium on Power Electronics, Electrical Drives, Automation and Motion (SPEEDAM), Anacapri, Italy, 22-24 June 2016. 
30. Di Clerico, M.; Caneponi, G.; Cazzato, F.; Cochi, S.; Falvo, M.C.; Manganelli, M. Planning studies for active distribution grids in presence of EVs charging stations: Simulation on a real test network. In Proceedings of the CIGRE 2016, Paris, France, 22-26 August 2016.

31. Di Clerico, M.; Caneponi, G.; Cazzato, F.; Cochi, S.; Falvo, M.C.; Manganelli, M. Active distribution grids and EV charging stations: A centralized approach for their integration. In Proceedings of the 2018 7th International Conference on Renewable Energy Research and Applications (ICRERA), Paris, France, 14-17 October 2018; pp. 1466-1471.

32. Di Clerico, M.; Caneponi, G.; Cazzato, F.; Cochi, S.; Falvo, M.C.; Manganelli, M. EV charging stations and RES-based DG: A centralized approach for smart integration in active distribution grids. Int. J. Renew. Energy Res. 2019, 9, 605-612.

33. Photovoltaic Geographical Information System. Available online: https://re.jrc.ec.europa.eu/pvg_tools/en/ tools.html\#TMY (accessed on 26 November 2019).

34. Blair, N.; DiOrio, N.; Freeman, J.; Gilman, P.; Janzou, S.; Neises, T.; Wagner, M. System Advisor Model (SAM) General Description (Version 2017.9.5); National Renewable Energy Laboratory: Golden, CO, USA, 2018; pp. 1-19.

35. Zimmerman, R.D.; Murillo-Sánchez, C.E. MATPOWER: User's Manual; Version 7.0b1; Power System Engineering Research Center, 2018; pp. 23-37. Available online: https://matpower.org/docs/manual.pdf (accessed on 19 February 2020).

36. Majidi Nezhad, M.; Groppi, D.; Laneve, G.; Marzialetti, P.; Piras, G. Oil Spill Detection Analyzing "Sentinel 2" Satellite Images: A Persian Gulf Case Study. World Congr. Civ. Struct. Environ. Eng. 2018. [CrossRef]

(C) 2020 by the authors. Licensee MDPI, Basel, Switzerland. This article is an open access article distributed under the terms and conditions of the Creative Commons Attribution (CC BY) license (http://creativecommons.org/licenses/by/4.0/). 